\title{
LATIHAN BANTUAN HIDUP DASAR BAGI IBU-IBU DI KECAMATAN SYIAH KUALA, KOTA BANDA ACEH
}

\author{
Hilman Syarif*, Jufrizal, Andara Maurissa \\ Fakultas Keperawatan Universitas Syiah Kuala, Banda Aceh \\ *email: hilmansyarif@unsyiah.ac.id
}

\begin{abstract}
Cardiac arrest outside the hospital is an emergency condition. Many reports of cardiac arrest leading to sudden death occur at home or in public spaces. These deaths were related to not getting adequate first aid and taking too long to get to the hospital. The purpose of this training was to increase community knowledge about basic life support for civil society, especially for women in Syiah Kuala Sub-district, Kota Banda Aceh. The training methods include lectures, video screenings, demonstrations and interactive discussions. The training participants were 42 women. After the training, participants' knowledge of basic life support was found to increase. A total of $95.2 \%$ of participants could answer $70 \%$ of the posttest questions correctly. Participants also stated that they were very satisfied with the training carried out. In conclusion, this training is effective for increasing knowledge about basic life support. Suggestions for the next training so that participants are given other emergency materials.
\end{abstract}

Keywords: civil society; basic life support; cardiac arrest

\begin{abstract}
Abstrak
Kejadian henti jantung di luar rumah sakit merupakan suatu kondisi gawat darurat. Banyak laporan kejadian henti jantung yang berujung kematian mendadak yang terjadi di rumah atau di ruang publik. Kematian tersebut berhubungan dengan tidak mendapatkan pertolongan pertama yang adekuat dan waktu yang terlalu lama untuk sampai di rumah sakit. Tujuan pelatihan ini adalah untuk meningkatkan pengetahuan masyarakat tentang bantuan hidup dasar bagi awam, terutama ibu-ibu di Kecamatan Syiah Kuala, Kota Banda Aceh. Metode pelatihan meliputi ceramah, pemutaran video, demonstrasi dan diskusi interaktif. Peserta pelatihan sebanyak 42 orang ibu-ibu. Setelah pelatihan ditemukan peningkatan pengetahuan peserta tentang bantuan hidup dasar. Sebanyak $95,2 \%$ peserta dapat menjawab $\geq 70 \%$ soal postes dengan benar. Peserta juga menyatakan sangat puas dengan pelatihan yang dilakukan. Kesimpulannya, pelatihan ini efektif untuk meningkatkan pengetahuan tentang bantuan hidup dasar. Saran untuk pelatihan berikutnya agar peserta diberikan materi kegawatdaruratan yang lain.
\end{abstract}

Kata Kunci: awam; bantuan hidup dasar; henti jantung

\begin{tabular}{l|l|l} 
Submitted: 2021-06-15 & Revised: 2021-07-10 & Accepted: 2021-07-31
\end{tabular}

\section{Pendahuluan}

Kasus henti jantung yang terjadi di luar rumah sakit merupakan masalah yang sangat sering terjadi di seluruh dunia dengan angka kejadian rata-rata 55 setiap 100.000 orang dewasa setiap tahun (Cho et al., 2014). Kondisi ini termasuk gawat darurat dan angka kejadiannya terus meningkat dari tahun ke tahun. Di Indonesia, angka kejadian henti jantung di luar rumah sakit belum ditemukan secara pasti, akan tetapi banyak laporan kejadian henti jantung yang berujung kematian mendadak yang terjadi di rumah atau di ruang publik (Muthmainnah, 2019). Kematian tersebut berhubungan dengan tidak mendapatkan pertolongan pertama yang adekuat dan waktu yang terlalu lama untuk sampai di rumah sakit (Villalobos et al., 2019).

Banyak kejadian korban tidak bisa diselamatkan saat sampai di rumah sakit, karena korban sudah meningal selama perjalanan menuju rumah sakit atau kondisi korban makin parah karena penolong pertama tidak kompeten dalam memberikan pertolongan. Ketidakmampuan dalam menangani korban umumnya disebabkan oleh kegagalan mengenal risiko, keterlambatan rujukan, kurangnya sarana yang memadai dan pengetahuan dan keterampilan masyarakat dalam mengenal keadaan risiko tinggi secara dini yang harus dilakukan secara efektif dan efisien. Kesalahan atau ketidaktepatan pemberian pertolongan pertama sebelum di rumah sakit juga dapat menyebabkan 
kecacatan atau kematian korban. Upaya yang harus dilakukan untuk meminimalkan angka kematian korban gawat darurat adalah dengan mempersingkat response time (Agustini et al., 2017; Darwati et al., 2016).

Oleh karena itu, meningkatkan pengetahuan dan keterampilan pertolongan pertama atau yang populer dikenal dengan bantuan hidup dasar (BHD) pada orang awam melalui pelatihan sangatlah penting. Permasalahan yang ada bahwa pelatihan BHD dan penggunaan defibrilator eksternal otomatis masih pada kalangan terbatas, masih difokuskan pada tenaga kesehatan (Yan et al., 2020; Matsui et al., 2019). Jika masyarakat awam mampu melakukan pertolongan pertama yang tepat termasuk BHD dan memangil ambulan segera, maka angka kematian di luar rumah sakit dapat diminimalkan (Villalobos et al., 2019).

Banyak penelitian yang mendukung hal tersebut, sebanyak $31,7 \%$ kondisi gawat darurat atau henti jantung dapat diselamatkan setelah mendapatkan pertolongan dari masyarakat awam yang terlatih. Menurut American heart association (2015) sebesar 40,1\% korban henti jantung di luar rumah sakit dapat diselamatkan karena terlebih dahulu mendapatkan BHD dari masyarakat awam yang terlatih (Mancini et al., 2015). Berdasarkan beberapa paparan tersebut, tim pengabdi melakukan upaya sosialisasi BHD pada masyarakat awam melalui pelatihan BHD bagi ibu-ibu di Kecamatan Syiah Kuala, Kota Banda Aceh.

\section{Metode}

Metode yang digunakan pada pengabdian kepada masyarakat ini adalah edukasi, pemutaran video, demonstrasi, dan diskusi interaktif. Pemilihan metode ini berdasarkan sudah banyak hasil penelitian yang mempublikasikan efektivitasnya.

Khalayak sasaran program ini adalah ibu-ibu di Kecamatan Syiah Kuala. Peserta sebanyak 42 orang. Latar belakang peserta sebagian besar adalah ibu rumah tangga dan belum pernah mendapatkan sosialisasi BHD. Kegiatan dilaksanakan di aula kantor camat kecamatan Syiah Kuala, pada tanggal 13 Pebruari 2020 (sebelum pandemi Covid-19).

Materi kegiatan yang disampaikan pada program ini adalah defenisi BHD, indikasi BHD, tanda henti napas, cara menentukan tingkat kesadaran korban, pusat-pusat bantuan jika terjadi gawat darurat, cara melakukan BHD, dan evaluasi BHD. Materi tersebut disampaikan oleh tim pengabdi dari Fakultas Keperawatan Universitas Syiah Kuala. Evaluasi peningkatan pengetahuan peserta dilakukan dengan pengisian soal sebelum kegiatan dan setelah kegiatan. Soal dalam bentuk pilihan berganda tersebut disusun sesuai dengan kapasitas peserta. Evaluasi kegiatan dilakukan dengan memberikan kuesioner kepada peserta.

Gambaran kegiatan dijelaskan pada beberapa tahap. Tahap 1, membina hubungan saling percaya. Pada tahap ini para tim pengabdi memperkenalkan diri, seperti nama, alamat, tempat bekerja, pengalaman kerja, dan keahlian. Tahap 2, peserta menjawab soal-soal pretes. Soal ini terdiri dari 10 soal yang disusun oleh tim pengabdi yang berisi tentang BHD. Soal ini diselesaikan sekitar 15 menit. Tahap 3, tim pengabdi menyampaikan materi BHD. Tahap 4, pemateri melakukan demonstrasi dan selanjutnya peserta redemonstrasi. Tahap 5, diskusi interaktif. Pada tahap ini peserta memberikan pertanyaan dan menjawab pertanyaan yang diberikan oleh narasumber. Tahap 6, evaluasi kegiatan.

Penyampaian materi BHD dan demonstrasi BHD oleh ahli dari tim pengabdi diikuti dengan antusias oleh para peserta, seperti ditunjukkan pada Gambar 1. 


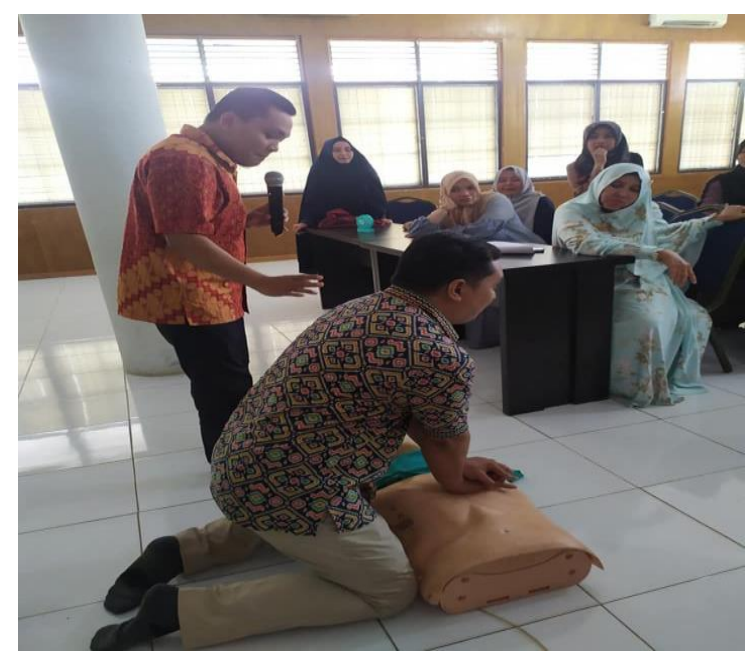

Gambar 1. Penyampaian materi dan demonstrasi

\section{Hasil dan Pembahasan}

Peningkatan pengetahuan peserta setelah program ini dilakukan dapat dilihat melalui perbedaan skor jawaban benar pada saat pretes dan postes. Hasil tersebut dapat dilihat pada Tabel 1.

Tabel 1. Perbandingan nilai pretes dan postes peserta pelatihan bantuan hidup dasar

\begin{tabular}{cccc}
\hline Nomor & Skor/ Nilai benar & Pretes & Postes \\
\hline 1 & 4 & 13 & 0 \\
2 & 5 & 15 & 0 \\
3 & 6 & 11 & 2 \\
4 & 7 & 3 & 16 \\
5 & 8 & 0 & 18 \\
6 & 9 & 0 & 5 \\
7 & 10 & 0 & 1 \\
Jumlah & & 42 & 42 \\
\hline
\end{tabular}

Tabel 1 menunjukkan bahwa terjadi peningkatan pengetahuan tentang BHD pada peserta pelatihan, setelah pelatihan sebanyak $95,2 \%$ peserta dapat menjawab soal dengan skor $\geq 7$. Hasil ini senada dengan program sebelumnya, bahwa peserta program tersebut mampu memahami materi penyuluhan tentang BHD, adanya peningkatan pengetahuan peserta antara sebelum dan setelah mendapatkan penyuluhan, serta peserta mampu mempraktikkan BHD dengan benar (Jurimi, Kaluku, \& Bumbungan, 2020). Hasil penelitian lain juga menyebutkan bahwa pelatihan secara signifikan meningkatkan pengetahuan dan keterampilan bantuan hidup dasar pada orang awam (Qadir, 2020).

Para ahli menjelaskan bahwa penyuluhan merupakan suatu cara yang efektif untuk meningkatkan pengetahuan, karena peserta dapat mendengarkan materi secara langsung dari sumbernya. Menurut Santosa \& Trisnain (2019), penyuluhan dan pelatihan merupakan upaya yang penting dilakukan untuk meningkatkan pengetahuan dan keterampilan masyarakat awam dalam memberikan pertolongan di area prehospital. Penyuluhan dan pelatihan ini baik diberikan sejak usia muda untuk menghasilkan generasi muda yang berkompeten dalam mengaplikasikan serta mensosialisasikan cara untuk memberikan pertolongan di area prehospital

Selain evaluasi pengetahuan peserta, evaluasi juga dilakukan terhadap tingkat kepuasan peserta terhadap sosialisasi yang dilakukan seperti ditunjukkan pada tabel 2 berikut. 
Tabel 2. Evaluasi kepuasan peserta terhadap program sosialisasi

\begin{tabular}{ccc}
\hline Nomor & Kriteria & Jumlah \\
\hline 1 & Sangat tidak puas & 0 \\
2 & Tidak puas & 0 \\
3 & Normal & 0 \\
4 & Puas & 10 \\
5 & Sangat puas & 32 \\
Jumlah & & 42 \\
\hline
\end{tabular}

Tabel 2 menunjukkan bahwa seluruh peserta menyatakan puas dan sangat puas terhadap penyuluhan yang diberikan. Hal ini juga terlihat dari antusias peserta untuk mendengarkan, bertanya, dan melakukan redemonstrasi prosedur BHD untuk orang awam. Redemonstrasi oleh peserta ditunjukkan pada Gambar 2 berikut.

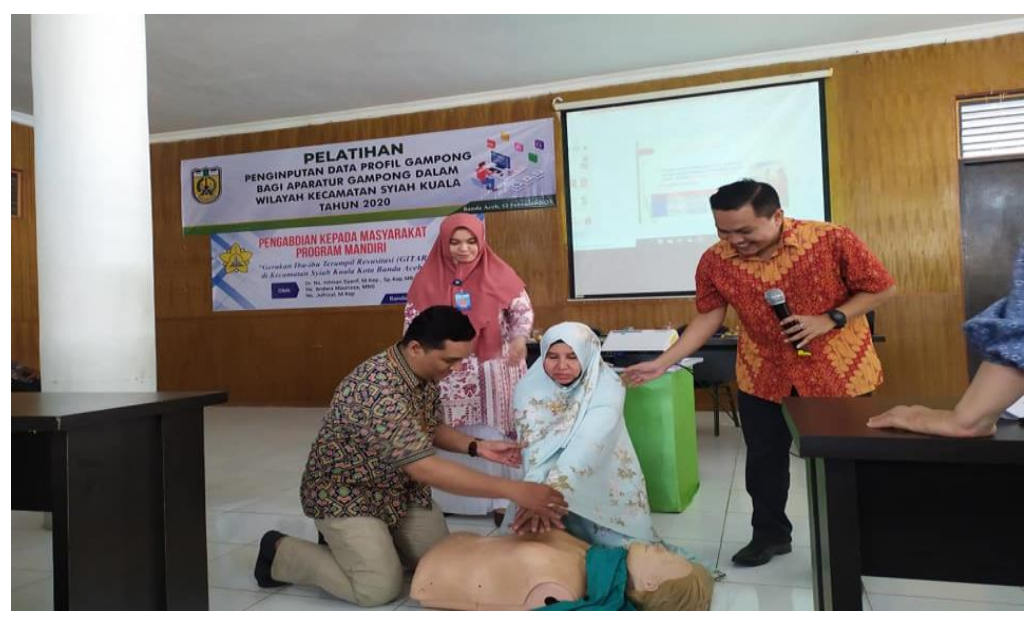

Gambar 2. Redemonstrasi BHD oleh peserta.

Keunggulan dari pelaksanaan program ini adalah materi yang disampaikan sangat sesuai dengan kondisi peserta. Selain itu, materi disampaikan dengan metode ceramah, pemutaran video, demonstrasi, dan redemontrasi. Sehingga memudahkan peserta untuk memahami materi yang disampaikan.

\section{Kesimpulan}

Kesimpulan adalah edukasi yang dilakukan efektif untuk meningkatkan pengetahuan ibu-ibu di Kecamatan Syiah Kuala tentang melaksanakan BHD dengan benar. Saran, agar program seperti ini dilakukan secara rutin untuk mempertahankan pengetahuan ibu-ibu, serta perlu dilakukan edukasi untuk kegawatdaruratan lainnya.

\section{Daftar Pustaka}

Agustini, N.L.P.I.B., Suyasa, I.G.P.D., Wulansari, N.T., Dewi, I.G.A.P.A., \& Rismawan, M. (2017). Penyuluhan dan pelatihan bantuan hidup dasar. Paradharma: Jurnal Aplikasi IPTEK. 1(2), 68-74

Cho, H., Moon, S., Park, S. J., Han, G., Park, J.-H., Lee, H., ... Bobrow, B. J. (2014). Out-of-hospital cardiac arrest: incidence, process of care, and outcomes in an urban city, Korea. Clinical and Experimental Emergency Medicine. 1(2), 94-100. 
Darwati, L.E., Desi, S.K., Sulisno, M. (2016). Karakteristik perawat IGD puskesmas. Jurnal I/miah Permas: Jurnal IImiah STIKES Kendal. 6(1), 22-27

Jurimi, S., Kaluku, S., \& Bumbungan, A. (2020). Peningkatan pengetahuan dan keterampilan melalui penyuluhan dan simulasi bantuan hidup dasar pada masyarakat awam pesisir di dusun Kasuari Desa Asilulu kecamatan Leihitu kabupaten Maluku Tengah. PengabdianMu: Jurnal Ilmiah Pengabdian kepada Masyarakat. 5(3), 264-269

Mancini, M. E., Diekema, D. S., Hoadley, T. A., Kadlec, K. D., Leveille, M. H., McGowan, J. E., ... Sinz, E. H. (2015). Part 3: Ethical issues: 2015 American Heart Association guidelines update for cardiopulmonary resuscitation and emergency cardiovascular care. Circulation. 132.

Matsui, S., Kitamura, T., Sado, J., Kiyohara, K., Kobayashi, D., Kiguchi, T., ... Sobue, T. (2019). Location of arrest and survival from out-of-hospital cardiac arrest among children in the public-access defibrillation era in Japan. Resuscitation. 140, 150-158.

Muthmainnah (2019). Hubungan tingkat pengetahuan awam khusus tentang bantuan hidup dasar berdasarkan karakteristik usia di RSUD X Hulu Sungai Selatan. Healthy-Mu Journal. 2(2). 31

Qadir, A. (2020). Efektifitas pelatihan dalam meningkatkan pengetahuan dan keterampilan bantuan hidup dasar pada orang awam. Jurnal IImiah Media Husada. 9(1), 15-20.

Santosa, W.R.B., Trisnain, A.N.S. (2019). Pengaruh pendidikan kesehatan pre-hospital stroke terhadap pengetahuan dan self-efficacy masyarakat dalam melakukan tindakan pertolongan pre-hospital stroke. Jurnal Gawat Darurat. 1(1), 31-36.

Villalobos, F., Del Pozo, A., Rey-Reñones, C., Granado-Font, E., Sabaté-Lissner, D., Poblet-Calaf, C., ... Flores-Mateo, G. (2019). Lay people training in CPR and in the use of an automated external defibrillator, and its social impact: A community health study. International Journal of Environmental Research and Public Health. 16(16).

Yan, S., Gan, Y., Jiang, N., Wang, R., Chen, Y., Luo, Z., ... Lv, C. (2020). The global survival rate among adult out-of-hospital cardiac arrest patients who received cardiopulmonary resuscitation: A systematic review and meta-analysis. Critical Care. 24(1), 8-13. 